\title{
Podemos discutir a avaliaçāo aberta em uma disciplina conservadora?
}

May we discuss open peer review in a conservative discipline?

Joāo Rodolfo Munhoz Ohara ${ }^{a}$

E-mail: ohara.jrm@gmail.com https://orcid.org/0000-0001-8946-4714 iD

a Universidade Federal do Rio de Janeiro, Instituto de História, Rio de Janeiro, 
Preocupadas, entre outras coisas, com crises graves de replicabilidade e de acessibilidade, as ciências vêm há tempos discutindo uma série de reformas das práticas de produção e circulação do conhecimento científico. Agrupadas sob a rubrica de "ciência aberta", essas mudanças incidem, entre outros aspectos, sobre o manejo e a disponibilidade dos dados de pesquisa ${ }^{1}$, o status dos manuscritos antes do processo formal de avaliação por pares (os tais "preprints", tornados famosos pela recente demanda de estudos sobre a COVID), assim como sobre o próprio peer review. O rótulo (do inglês, open science) já nos dá alguma ideia do (não-)lugar das humanidades no processo, uma vez que a cultura acadêmica anglófona não inclui as humanities no escopo das sciences. Essa exclusão não é diferente aqui, no Brasil, onde periódicos e pesquisadores das humanidades são muito mais arrastados pelas exigências cada vez mais estritas dos indexadores internacionais e dos órgãos de fomento do que atores do processo de reconfiguração das nossas práticas de produção e circulação de conhecimento. Não nos deveria surpreender, portanto, que várias dessas reformas pareçam não se adequar às práticas disciplinares a que estamos acostumados.

Acompanhando as preocupações das editorias com as quais tenho mais contato, gostaria de me deter por alguns parágrafos em uma dessas reformas que produz um desconforto tanto entre os colegas mais jovens quanto entre os mais experientes - a avaliação por pares, particularmente quando se fala de "open peer review". A avaliação por pares é um dos mecanismos centrais da maquinaria contemporânea de produção de conhecimento acadêmico e científico. Tal como a conhecemos, sua história é muito mais recente do que se supõe. Só na segunda metade do século XX o sistema se tornou parte incontornável e insubstituível da comunicação científica em periódicos, consolidandose como um garantidor de relevância e de qualidade do trabalho publicado. ${ }^{2}$ Entre nós, historiadores brasileiros, a história dessa prática parece contar com marcos cronológicos ainda mais recentes. ${ }^{3} \mathrm{E}$ parte da credibilidade do sistema é dada, ou assim o cremos, pela possibilidade do parecer "duplo-cego" (uma tradução literal do "double-blind" que soa estranha, mas à qual acabamos por nos acostumar), em que as identidades de autores e pareceristas são mantidas permanentemente em sigilo. Presume-se que tal característica seja do interesse de todas as partes - protegendo

\footnotetext{
${ }^{1}$ De que falou, recentemente, Valdei Araujo (2021) no editorial da Revista Brasileira de História.

2 A versão mais conhecida da história da "origem" do sistema de peer review remete a Henry Oldenburg e às Philosophical Transactions, da Royal Society, mas trabalhos como os de Melinda Baldwin (2015; 2018) e Alex Csiszar (2018) vêm demonstrando que o refereeing de então tem pouca relação com o moderno peer review.
}

3 Como notou Wagner Geminiano dos Santos (2018, p. 85 e 131). 
autores e pareceristas dos persistentes vieses cognitivos em um mundo acadêmico constituído por relações assimétricas de poder.

Em outro front, a elaboração do parecer é uma faceta do nosso trabalho para a qual nunca ou raramente recebemos algum tipo de treinamento formal. Tudo que temos para nos guiar são aqueles que nós mesmos recebemos ou dos quais ouvimos falar pelo testemunho de colegas. Não é surpreendente, aqui também, que ocasionalmente nos deparemos com pareceres pouco profissionais, cheios de comentários agressivos, rudes ou condescendentes - ainda que, por sorte, também haja aqueles tão detalhados, tão cuidadosos e tão generosos que mereceriam uma condecoração à parte. Suponho que muitos de nós aspirem a fazer bons pareceres, apesar de todas as nossas limitações e de só aprendermos "o que é um bom parecer" de maneira muito informal, mas esse objetivo nem sempre é alcançável. Tendo em vista tal cenário, os formulários de avaliação das revistas têm se tornado mais detalhados, especificando aos pareceristas os itens que cada periódico considera relevantes para tomar a decisão final sobre o manuscrito.

Ainda que o termo "avaliação aberta" possa indicar diretrizes muito diferentes a depender do contexto, o mais comum é que se refira a dois aspectos que podem, mas não precisam, vir juntos: (1) a publicação do conteúdo dos pareceres e (2) a identificação de autores e/ou de pareceristas. Alguns periódicos estrangeiros vêm testando diferentes formatos, mas os limites quantitativos e disciplinares desses experimentos prejudicam qualquer tentativa de análise. Na falta de evidências seguras, por vezes contamos com nossas intuições mais ou menos informadas para pensarmos a questão, e a resposta inicial dos nossos colegas historiadores geralmente é defensiva, para não dizer conservadora. Ainda que reconheçam os problemas atuais (como a falta de reconhecimento do trabalho dos pareceristas ou as condutas eticamente ou profissionalmente inadequadas que o anonimato torna possível), alguns colegas temem, por exemplo, que o fim do "duplo-cego" possa tornar reais as consequências indesejáveis que motivaram a adoção desse modelo no passado. Outro receio é o de que a publicação dos pareceres (de qualquer forma que seja feita) obedece tão somente à cultura de auditoria, que tenta transformar todas as atividades em índices de produtividade. Assim como no caso da disponibilização pública dos dados de pesquisa, ainda não estão claros para os praticantes da disciplina nem os eventuais benefícios de mudanças no sistema de avaliação por pares, nem as formas mais adequadas de lidar com os problemas amplamente reconhecidos do sistema atual e com as propostas exógenas, que por vezes não levam em conta as necessidades da nossa área. 
O imperativo da ampliação da acessibilidade e da transparência das nossas práticas de produção e circulação de conhecimento é, de fato, característico de um presente obcecado pelo controle técnico e pouco tolerante de (certas) zonas de opacidade. Dito isso, parece-me crucial colocarmos em pauta a adequação dos modelos de "ciência aberta" às nossas necessidades e, por que não, propormos os ajustes que considerarmos mais apropriados a elas. No caso da avaliação por pares, é importante que nos mantenhamos sensíveis às especificidades de uma disciplina tão diversa quanto a história. O receio de represálias e o potencial de autocensura por parte de colegas mais jovens são preocupações compartilhadas por todas as áreas do conhecimento, mas parecem ser especialmente danosas em uma disciplina em que controvérsias interpretativas são mais comumente abandonadas do que solucionadas, ou em que diferenças teóricas tendem a produzir mais silenciamentos do que debates. Por outro lado, o anonimato do autor é frágil em áreas com menor número de especialistas ou, pior, mediante uma busca simples na internet - este, um problema novo e que, com certeza, não estava no horizonte quando da criação do "duplo-cego".

Quanto à publicação do conteúdo dos pareceres, com ou sem identificação, convém considerar outros aspectos. Um primeiro exemplo é o local de publicação: seriam anexados ao artigo ou disponibilizados como recursos extras nos websites? Essa pergunta é particularmente relevante considerando que a maioria das revistas da nossa área, ainda que contem com a publicação digital, permanecem formatadas pelos limites da publicação analógica (separando volumes e números dos fascículos, atribuindo paginação sequencial, com pouco uso de recursos multimídia ou hiperlinks etc.). Seriam publicadas também eventuais respostas dos autores às considerações dos pareceristas? Qual o estatuto desses novos materiais em termos de referenciação e arquivamento? Uma vez consentida por pareceristas e autores, a publicação dos pareceres seria de decisão discricionária dos editores? Só o conjunto dos historiadores pode responder tais questões e oferecer sugestões mais adequadas às suas necessidades.

O modelo de ciência aberta capitaneado a partir das ciências traz elementos que certamente precisarão passar por adequações. No caso dos dois principais sentidos da avaliação aberta, convém discutir coletivamente a respeito dos ganhos potenciais (o desincentivo aos pareceres grosseiros e pouco profissionais, a atribuição, reconhecimento e responsabilização dos pareceristas e do seu trabalho, a riqueza substantiva presente nas análises críticas dos pareceristas etc.) e dos riscos envolvidos (retaliação a colegas mais jovens ou em posições menos prestigiosas, autocensura motivada pelo medo). Pressionados pelos indexadores e pelas agências de fomento, os periódicos da área têm incentivado tal discussão para que não sejamos simplesmente atropelados por 
exigências pouco adequadas às nossas práticas. Devemos discutir o que é uma "política de dados de pesquisa" em história, como sugeriu Valdei Araujo, e devemos discutir também que tipo de abertura é possível na avaliação por pares - publicar os pareceres, mas manter o anonimato? Abrir completamente as informações? Manter o modelo atual, tolerando as condutas pouco profissionais que o anonimato torna possíveis? Há ainda outros aspectos que precisamos esclarecer - como o problema dos preprints, a pouca familiaridade dos historiadores com os padrões de metadados estabelecidos na arquivologia e na biblioteconomia, bem como a ausência de padrões próprios aos historiadores etc. Ainda que Anthony Grafton estivesse certo sobre o papel das notas de rodapé na maquinaria do historiador, resta o problema de que as transformações das instituições de guarda e de produção de conhecimento impõem uma reflexão profunda sobre essa função referencial que a nota de rodapé ocupou nos últimos séculos. 0 historiador não precisa nem deve ser um refém do seu presente, à deriva na correnteza que o carrega, mas também não pode (porque não é possível) supor que suas práticas disciplinares sejam imunes às críticas e às transformações que surgem tanto de dentro do seu campo quanto de fora dele. Que se abandone a tática fabiana.

\section{REFERÊNCIAS}

ARAUJO, Valdei Lopes de. Editorial: O Papel dos Periódicos na Publicação de Dados de Pesquisa. Revista Brasileira de História, São Paulo, v. 41, n. 86, p. 7-9, 2021.

BALDWIN, Melinda. Credibility, Peer Review, and Nature, 1945-1990. Notes and Records: The Royal Society Journal of the History of Science, London, v. 69, n. 3, p. 337-352, 2015.

BALDWIN, Melinda. Scientific Autonomy, Public Accountability, and the Rise of "Peer Review" in the Cold War United States. Isis, Notre Dame (US), v. 109, n. 3, p. 538-558, 2018.

CSISZAR, Alex. The Scientific Journal: authorship and the politics of knowledge in the nineteenth century. Chicago: Chicago University Press, 2018. 
SANTOS, Wagner Geminiano dos. A Invenção da Historiografia Brasileira Profissional, Acadêmica: geografia e memória disciplinar, disputas políticoinstitucionais e debates epistemológicos acerca do saber histórico no Brasil (1980-2012). 2018. Tese (Doutorado em História) - Programa de Pós-Graduação em História, UFPE, Recife, 2018.

\section{INFORMAÇŌES ADICIONAIS}

\section{BIOGRAFIA PROFISSIONAL}

João Ohara é professor de teoria da história no Instituto de História e do Programa de PósGraduação em História Social (PPGHIS) da UFRJ. Tem experiência na área de teoria e filosofia da história e de história da historiografia, com ênfase em temas ligados à ética e à epistemologia da história. É o organizador, programador e mantenedor do Catálogo Histórico de Teses e Dissertações da área de História. Atualmente desenvolve pesquisa sobre virtudes epistêmicas e o problema da confiança na aquisição e transmissão de conhecimento histórico.

\section{ENDEREÇO PARA CORRESPONDÊNCIA}

Instituto de História - Largo São Francisco de Paula, $\mathrm{n}^{\circ} 1,2^{\circ}$ andar, Centro, Rio de Janeiro/RJ, 20051-070, Brasil.

\section{FINANCIAMENTO}

Não se aplica.

\section{CONFLITO DE INTERESSES}

Nenhum conflito de interesse declarado.

\section{APROVAÇĀO EM COMITÊ DE ÉTICA}

Não se aplica.

\section{MODALIDADE DE AVALIAÇĀO}

Não avaliado.

\section{EDITORES RESPONSÁVEIS}

Não se aplica. 
DIREITOS AUTORAIS

Copyright (c) 2020 História da Historiografia: International Journal of Theory and History of Historiography.

LICENÇA

Este é um artigo distribuído em Acesso Aberto sob os termos da Licença Creative Commons Atribuição-NãoComercial-SemDerivações 4.0 International. 